\title{
DESAIN DAN IMPLEMENTASI JARINGAN KOMPUTER BARU UNTUK MENINGKATKAN KUALITAS KOMUNIKASI DATA PADA KAMPUS B RAWAMANGUN UNIVERSITAS NEGERI JAKARTA
}

\author{
Aditya Faishol Robbani ${ }^{1}$, M. Ficky Duskarnaen. M.Sc ${ }^{2}$, Hamidillah Ajie,S.Si.,MT ${ }^{3}$ \\ ${ }^{1}$ Mahasiswa Prodi PendidikanTeknik Informatika dan Komputer, Teknik Elektro, FT - UNJ \\ ${ }^{2,3}$ Dosen Prodi Pendidikan Teknik Informatika dan Komputer, Teknik Elektro, FT - UNJ \\ 1'adityafaisholrobbani@gmail.com, ${ }^{2}$ duskarnaen@unj.ac.id, ${ }^{3}$ hamidillah@unj.ac.id
}

\begin{abstract}
Abstrak
Tujuan dari penelitian ini adalah untuk mendesain dan mengimplementasikan jaringan komputer baru untuk meningkatkan kualitas komunikasi data dengan sasaran penelitian pada kampus B Universitas Negeri Jakarta. Penelitian ini dilaksanakan melalui tahapan pengamatan menggunakan paramater yang ditentukan, yaitu: throughput dan kecepatan Internet. Setelah tahap pengamatan selesai, selanjutnya dilakukan desain dan implementasi berdasarkan pengamatan yang telah dilakukan dan persetujuan dari UPT TIK UNJ. Implementasi berupa mengubah jenis komunikasi data menggunakan layer 2 dan pergantian perangkat jaringan yang telah melewati MTBF. Pengujian dilakukan dengan menggunakan metode yang sama pada tahap pengamatan untuk mengetahui hasil implementasi. Hasil penelitian menunjukkan terjadi peningkatan throughput dan kecepatan Internet pada kampus B UNJ. Analisis penelitian menunjukkan kecepatan Internet yang didapat juga telah memenuhi standar AT\&T sebesar 1,5 Mbps serta survei kepuasan mahasiswa terhadap jaringan komputer di kampus B menunjukkan cukup untuk mendukung kegiatan kampus. Dapat disimpulkan bahwa dengan menggunakan tahapan yang telah disebutkan dapat meningkatkan kualitas komunikasi data pada kampus B Universitas Negeri Jakarta.
\end{abstract}

Kata kunci : Desain dan Implementasi, throughput, kecepatan Internet, layer, MTBF.

\section{Pendahuluan [Times New Roman 10, bold]}

Perguruan tinggi atau universitas kini mengandalkan jaringan komputer di setiap pelaksanaan layanannya. Universitas dalam pelaksanaan pelayanannya, menggunakan jaringan komputer sebagai pendukung layanan akademik, seperti sistem informasi akademik (siakad), maupun sebagai pendukung pada bidang non-akademik seperti absensi karyawan dan layanan hostspot mahasiswa. Setiap tahunnya, universitas selalu menerima mahasiswa/i baru yang jumlahnya tidaklah sedikit. Sehingga, makin banyak pengguna jaringan, maka penggunaan beban jaringan juga makin berat. Oleh karena itu, diperlukan adanya peningkatan dalam hal kualitas jaringan tersebut. Namun, peningkatan layanan tersebut memerlukan sebuah penelitian apakah jaringan komputer yang dibutuhkan sudah sesuai atau belum.

Sama dengan kampus lainnya, kampus B juga menggunakan jaringan dalam pelaksanaan layanannya. Pada saat ini, seiring dengan kebutuhan administrasi kampus, dan ditambah dengan pengguna jaringan yang makin banyak, beban jaringan yang ada pun meningkat, sehingga mengganggu kinerja layanan yang ada. Kualitas jaringan (throughput) yang ada dirasa kurang optimal untuk memenuhi kebutuhan di kampus B, yaitu hanya 30-40 Mbps (yang didapatkan saat observasi). Oleh sebab itu, diperlukan adanya peningkatan kualitas jaringan untuk mendukung segala layanan yang ada di Kampus B UNJ tersebut.

Selain itu, banyaknya masalah dan aduan yang ditujukan kepada Unit Pelaksana Terpadu Teknologi Informasi dan Komputer (UPT TIK) mengenai keadaan jaringan di kampus B. Masalah pada jaringan komputer tersebut, meliputi absensi karyawan yang tidak terekam, jaringan komputer pada sistem akademik yang sering mengalami putus koneksi/tidak stabil yang juga terjadi di jaringan komputer pada sistem keuangan FIO. Dari permasalahan tersebut ditemukan beberapa faktor seperti hampir seluruh port (14 dari 24 port) dari perangkat switch rusak dan dalam sehari terjadi putus sambungan di jaringan komputer sebanyak 2-3 kali pada jam sibuk.

Jaringan pada kampus B saat ini menggunakan router sebagai piranti utamanya, namun penerapannya di UNJ masih belum sesuai dengan kebutuhannya, yaitu hanya mencapai kecepatan Internet 4-6 Mbps saja. Sedangkan, optimalnya untuk sebuah kampus memiliki kecepatan Internet 100Mbps. Data sebagai parameter yang diambil dalam perbandingan meliputi throughput, kecepatan Internet, serta waktu yang diperlukan untuk 
mentransfer data dengan jenis file dan ukuran data tertentu. .

\section{Dasar Teori}

\subsection{Komunikasi Data}

Komunikasi data menggabungkan beberapa teknik dan teknologi dengan tujuan utama untuk memungkinkan segala bentuk komunikasi elektronik. Teknologi ini meliputi telekomunikasi, jaringan komputer dan komunikasi radio atau satelit. Komunikasi data biasanya membutuhkan adanya media transportasi atau komunikasi antara node yang ingin berkomunikasi satu sama lain, seperti kawat tembaga, kabel serat optik atau sinyal nirkabel. (sumber https://www.techopedia.com/ definition/ $6765 /$ data- communications -dc diakses pada tanggal 19 januari 2018)

\subsubsection{Throughput}

Menurut Behrouz A. Forouzan (2007: 8), performa dari suatu jaringan sering diukur dari dari dua parameter yaitu throughput dan delay. Harapannya dari sebuah jaringan adalah throughput yang lebih besar dan delay yang kecil. Namun, kedua parameter ini berbanding terbalik, jika mengirim data yang lebih besar ke jaringan, ini akan meningkatkan throughput tetapi juga dapat meningkatkan delay karena meningkatkan kepadatan lalu lintas jaringan.

\subsubsection{Bandwidth}

Menurut David Barnett, dkk (2004: 38), bandwidth kabel adalah frekuensi maksimum dimana data dapat ditransmisikan dan diterima secara efektif. Kecepatan bit tergantung pada jaringan elektronik, bukan kabel, asalkan frekuensi operasi jaringan berada dalam bandwidth yang dapat digunakan oleh kabel. Dengan kata lain, kabelnya hanya berupa pipa. Pikirkan bandwidth sebagai diameter pipa. Jaringan elektronik memberikan tekanan air. Salah satu tetesan datang melalui atau gusher, tapi diameter pipa tidak berubah.

\subsubsection{Standar Kecepatan Internet}

Tabel dibawah ini menunjukan tingkat kecepatan download yang direkomendasikan untuk menjalankan aktivitas pada sebuah perangkat. (sumber https://www.att.com/esupport/speedcalculator/index.jsp diakses pada tanggal 10 Desember 2017).

\begin{tabular}{|l|l|}
\hline Aktivitas & $\begin{array}{l}\text { Kecepatan download yang } \\
\text { direkomendasikan }\end{array}$ \\
\hline Email & $0,5 \mathrm{Mbps}$ \\
\hline Music streaming & $0,5 \mathrm{Mbps}$ \\
\hline Web browsing & $1 \mathrm{Mbps}$ \\
\hline Web conferencing & $4 \mathrm{Mbps}$ \\
\hline $\begin{array}{l}\text { Standard video } \\
\text { streaming }\end{array}$ & $1,5 \mathrm{Mbps}$ \\
\hline HD video straming & $4 \mathrm{Mbps}$ \\
\hline Gaming & $4 \mathrm{Mbps}$ \\
\hline
\end{tabular}

Tabel 2.1 AT\&T Standard Internet Speed

\subsection{Kampus B UNJ}

Kampus B UNJ, berlokasi di Jalan Pemuda, Rawamangun, Jakarta Timur. Kampus B terpisah jarak dengan kampus A sejauh 1,9 km. Kampus B diperuntukan untuk FIO. FIO merupakan salah satu dari 8 (delapan) fakultas yang ada di UNJ, dengan jumlah mahasiswa sebanyak 2.204 orang, 81 dosen dengan status Pegawai Negeri Sipil (PNS), 2 orang dosen tetap non PNS, 2 orang dosen dengan perjanjian kontrak, dan 63 orang tenaga administrasi (18 PNS dan 45 honorer).

FIO UNJ memiliki 5 (tiga) Program Studi, yang terdiri atas (1) Program Studi Pendidikan Jasmani Kesehatan dan Rekreasi, (2) Program Studi Pendidikan Kepelatihan Olahraga, (3) Program Studi Ilmu Keolahragaan, (4) Program Studi Olahraga Rekreasi, dan (5) Program studi Kepelatihan Kecabangan Olahraga. (Sumber http://fik.unj.ac.id/? page_id=1011 diakses pada tangal 19 Desember 2017).

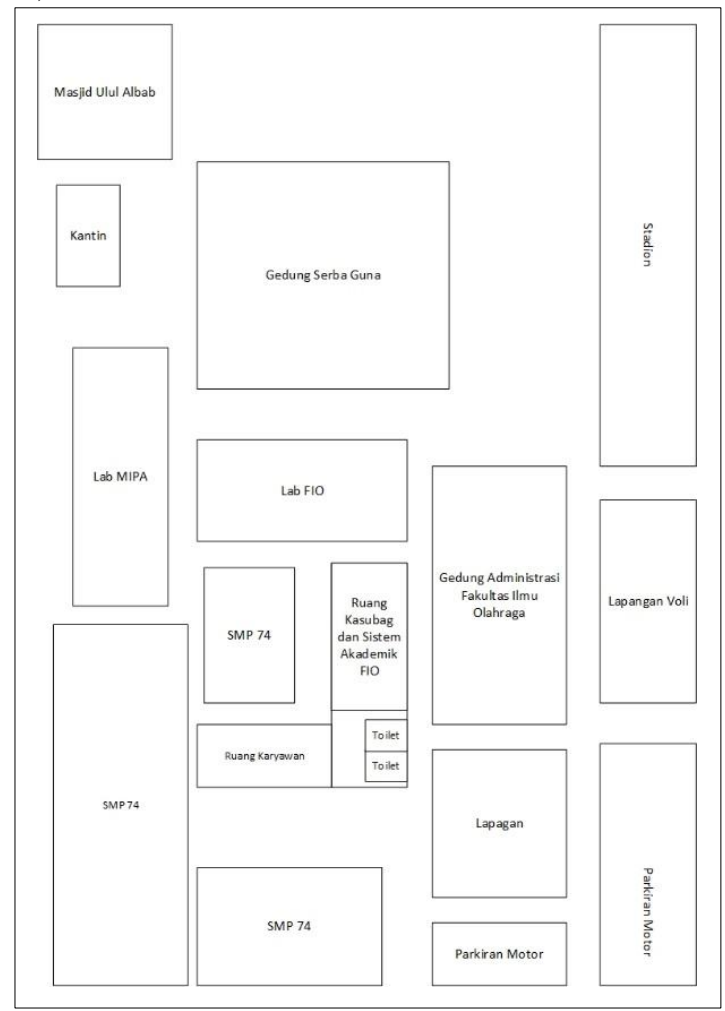

Gambar 2.1 Denah Kampus B UNJ

Kondisi layanan TIK yang berjalan di kampus B belum mencapai keadaan optimal, tidak semua pengguna dapat mengakses jaringan secara bersamaan (access point yang disediakan hilang), dan alokasi bandwidth backbone yang hanya sebesar 30-40 Mbps belum mencukupi kebutuhan yang ada (100-150 Mbps).

\subsection{Jaringan Komputer}

Menurut Tanenbaum \& Wetherall (2011: 9), jaringan komputer adalah penggabungan antara komputer dengan komunikasi pada sistem komputer yang terorganisir. Konsep "pusat komputer" sebagai 
ruang dengan komputer besar dimana pengguna membawa pekerjaan mereka untuk diproses. Model dari satu komputer yang melayani semua organisasi komputasi telah digantikan dengan komputer dengan jumlah besar saling terhubung dan melakukan pekerjaan.

\subsubsection{Routing}

Menurut Tanenbaum \& Wetherall (2011: 362 364), routing terdapat di berbagai jenis jaringan, termasuk jaringan telepon, jaringan komputer, Internet, dan juga jaringan transportasi. Dalam jaringan komputer, routing adalah bagian dari lapisan network yang menentukan kemana pengiriman paket yang masuk. Proses routing biasanya meneruskan paket berdasarkan tabel routing yang telah disimpan sebagai catatan rute ke berbagai tujuan jaringan. Oleh sebab itu, penting untuk membuat tabel routing yang tersimpan dalam memori router untuk routing yang lebih efisien, sebagian besar routing hanya menggunakan satu jalur jaringan dalam satu waktu.

\subsubsection{Switching}

Switching dapat diartikan sebagai pengalihan jaringan. Switching berasal dari prinsip kerja sakelar yang digunakan untuk menghidupkan atau mematikan perangkat. Dalam jaringan, switching digunakan untuk menghubungkan beberapa perangkat dalam satu jaringan yang sama. (Empson \& Schmidt, 2014: 35)

\subsubsection{Mean Time Between Failure (MTBF)}

MTBF adalah waktu rata-rata perangkat atau perangkat beroperasi sebelum terjadi kegagalan. Nilai ini terkadang dihasilkan oleh produsen perangkat itu sendiri, namun tidak semua produsen perangkat memberikan nilai tersebut, sehingga pemilik perangkat harus menghasilkan nilai MTBF dari kinerja terakhir peralatan. Meskipun setiap perangkat berbeda, makin panjang waktu rata-rata antara kegagalan atau MTBF maka akan makin baik, White (2011)

MTBF dapat digunakan untuk memprediksi harapan hidup perangkat dalam hitungan jam. Pada perangkat jaringan, beberapa produsen perangkat memberikan informasi MTBF pada casing perangkat tersebut. Mengingat perangkat di kampus D Universitas Negeri Jakarta (UNJ) sudah lama tidak mengalami perbaikan maupun peningkatan, perlu adanya pengamatan MTBF perangkat jaringan yang ada (switch, router) yang akan berpengaruh terhadap kualitas komunikasi data.

\subsubsection{Leased Line}

leased line adalah koneksi yang menyediakan +layanan yang dedicated, koneksi point-to-point antara dua lokasi, Cioara, dkk. (2008). Kelebihan dari koneksi leased line adalah koneksi dedicated yang menyediakan bandwidth yang besar, memberikan konektivitas yang berkualitas tinggi, serta latency, dan jitter yang kecil karena tidak memerlukan enkripsi yang dapat meningkatkan kinerja prosesor atau memori pada router.

\section{Metodologi}

Alat dan bahan penelitian ini ditunjukkan pada Tabel 3.1.

Tabel 3.1 Alat dan Bahan Penelitian

\begin{tabular}{|c|c|c|c|}
\hline \multicolumn{4}{|c|}{ Perangkat Keras } \\
\hline No & Perangkat & Komponen & Keterangan \\
\hline 1 & $\begin{array}{l}\text { Switch Fengine S2208G-PAF } \\
\text { gigabit Ethernet }\end{array}$ & Port & $\begin{array}{l}\text { 8-port RJ45, manageable } \\
\text { switch }\end{array}$ \\
\hline 2 & $\begin{array}{l}\text { Switch Cisco Catalyst } 2960-\mathrm{X} \\
\text { series LAN base 10G uplink }\end{array}$ & Port & $\begin{array}{l}24 \text { Gigabit Ethernet } \\
\text { Ports, access switch }\end{array}$ \\
\hline 3 & $\begin{array}{l}\text { Switch Cisco Catalyst } 385012 \mathrm{~S} \text { E } \\
\text { series }\end{array}$ & Port & $\begin{array}{l}12 \text { Gigabit Ethernet } \\
\text { Ports, distribution switch }\end{array}$ \\
\hline \multirow[t]{3}{*}{4} & \multirow[t]{3}{*}{ PC Server } & Prosesor & $\begin{array}{l}\text { Pentium Dual-Core CPU } \\
\text { E5400 } 2.70 \mathrm{GHz}\end{array}$ \\
\hline & & RAM & $2 \mathrm{~GB}$ \\
\hline & & Harddisk & $250 \mathrm{~GB}$ \\
\hline \multirow[t]{3}{*}{5} & \multirow[t]{3}{*}{ Laptop Asus A46CB } & Prosessor & $\begin{array}{c}\text { Intel Core i3-3217U } 1.80 \\
\mathrm{GHz}\end{array}$ \\
\hline & & RAM & $8 \mathrm{~GB}$ \\
\hline & & Harddisk & $500 \mathrm{~GB}$ \\
\hline \multicolumn{4}{|c|}{ Perangkat Lunak } \\
\hline No & Nama & & Fungsi \\
\hline 1 & $\begin{array}{c}\text { Browser Mozilla Firefox yersi } \\
\text { Ouantum } 57.0 .2\end{array}$ & \multicolumn{2}{|c|}{ Tes kecepatan Internet } \\
\hline 2 & Windows Server 2008 Standard 32 & \multicolumn{2}{|c|}{ Sistem Operasi Server } \\
\hline 3 & Windows 10 Enterprise 64 bit & \multicolumn{2}{|c|}{ Sistem Operasi Laptop Asus } \\
\hline
\end{tabular}

Metode untuk perancangan dan implementasi peningkatan kualitas komunikasi data di kampus B UNJ menggunakan pendekatan top-down network design yang di sebagai berikut:

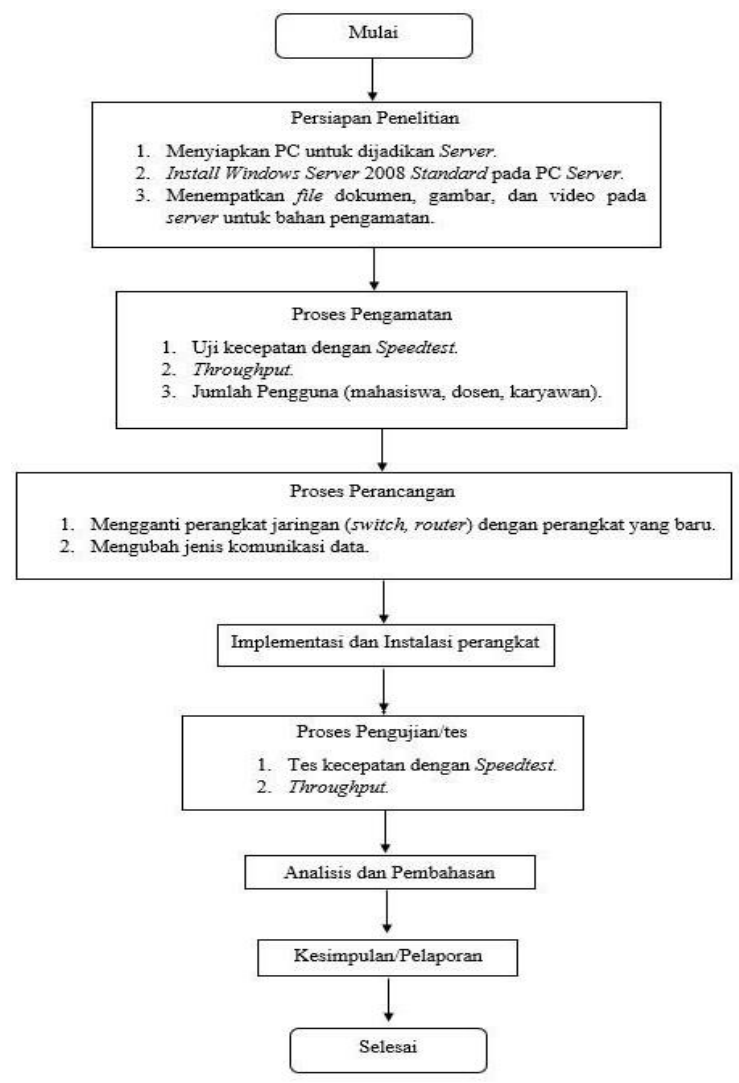

Gambar 3.1 Diagram Penelitian 


\section{Hasil dan Analisis}

\subsection{Hasil Desain Topologi}

Hasil desain topologi yang diterapkan pada kampus B UNJ seperti ditunjukkan pada Gamber 4.1.

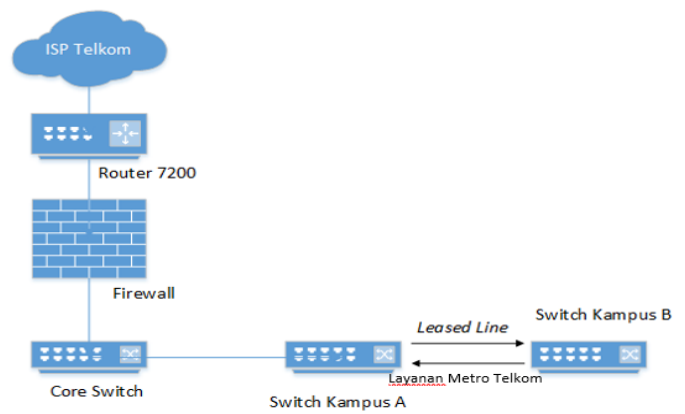

Gambar 4.1 Desain Topologi Kampus B

Desain topologi di atas menunjukkan juga pergantian perangkat yang baru yaitu menggunakan switch Cisco Catalyst $285012 \mathrm{~S}$ di kampus B, sebelumnya menggunakan router. Penggunaan switch tersebut bertujuan untuk meningkatkan kualitas jaringan lokal antara kampus A dengan B, penambahan kapasitas yang yang lebih besar serta koneksi yang sebelumnya menggunakan layer 3 menjadi menggunakan layer 2.

\subsection{Hasil Pengujian Througput}

Hasil dari pengujian seperti ditunjukkan dengan grafik menggunakan satuan Megabit per second (Mbps) pada Gambar 4.2

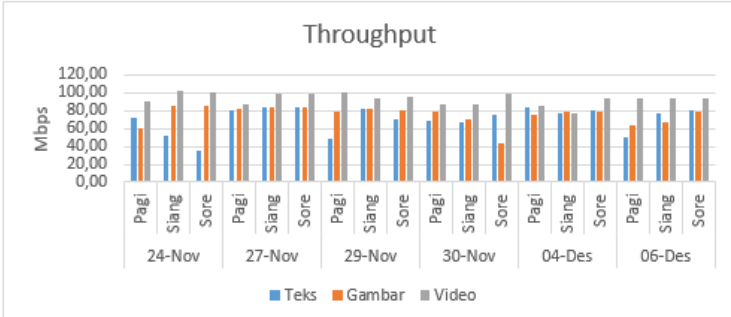

Gambar 4.2 Hasil Pengujian Throughput

Rata-rata dari pengujian throughput ditunjukkan pada Table 4.1

\begin{tabular}{|c|c|}
\hline Jenis File & Rata-rata throughput \\
\hline Dokumen & $70,54 \mathrm{Mbps}$ \\
\hline Gambar & $75,54 \mathrm{Mbps}$ \\
\hline Video & $93,43 \mathrm{Mbps}$ \\
\hline
\end{tabular}

Tabel 4.1 Hasil Pengujian rata-rata Throughput

\subsection{Hasil Survei Kepuasan Mahasiswa}

Selain melakukan perbandingan throughput, penulis juga menggunakan hasil survei yang disetujui dan disebar secara online ke mahasiswa Fakultas
Ilmu Olahraga menggunakan form office yang tersedia dan bisa diakses oleh siapapun. Survei kepuasan ini dibagi menjadi 5 rating, rating tersebut menunjukkan nilai 1 sangat tidak puas sampai nilai 5 sangat puas. Target dari survei ini untuk mengetahui kepuasan mahasiswa mengenai Internet yang ada di kampus B UNJ. Tabel 4.2 berikut ini hasil dari survei yang dilakukan berkaitan dengan dampak dari penelitian ini.

Tabel 4.2 Hasil Survei Kepuasan Mahasiswa

\begin{tabular}{|c|c|c|c|}
\hline No & Penilaian & Jumlah Suara & Kepuasan \\
\hline 1 & Browsing & & $64 \%$ \\
\hline 2 & Streaming & \multirow{4}{*}{40 Mahasiswa } & $63 \%$ \\
& Download & $66 \%$ \\
\hline 4 & Upload & & $66 \%$ \\
\hline
\end{tabular}

\subsection{Analisis Data Penelitian}

Data dari hasil pengujian yang didapatkan maka akan dilakukan perbandingan dengan standar yang telah ditetapkan oleh AT\&T sebagai standar kecepatan yang dimiliki untuk aktivitas tertantu. Standar AT\&T menggunakan Download Speed Calculator yang merupakan metode perhitungan yang dapat dipilih berdasarkan aktivitas penggunaan. Pada penelitian ini penulis hanya membandingkan kecepatan yang didapat dengan standar AT\&T untuk penggunaan browsing dan e-mail, karena kedua aktivitas tersebut yang paling banyak dan berhubungan dengan kegiatan administrasi ataupun akademik kampus.

Tabel 4.3 Perbandingan Hasil Pengujian Dengan Standar AT\&T

\begin{tabular}{|c|c|c|c|c|}
\hline Hari/Tanggal & Waktu & $\begin{array}{c}\text { Kecepatan } \\
\text { Internet }\end{array}$ & $\begin{array}{l}\text { Standar } \\
\text { AT\&T }\end{array}$ & Terpenuhi \\
\hline \multirow{3}{*}{$\begin{array}{c}\text { Jum'at, } 24 \\
\text { November } 2017\end{array}$} & Pagi & $122,07 \mathrm{Mbps}$ & \multirow{18}{*}{$\begin{array}{c}90 \mathrm{Mbps} \\
(60 \mathrm{User} \\
\times 1,5=90 \\
\mathrm{Mbps})\end{array}$} & $\mathrm{Ya}$ \\
\hline & Siang & $122,05 \mathrm{Mbps}$ & & Ya \\
\hline & Sore & $131,81 \mathrm{Mbps}$ & & $Y_{a}$ \\
\hline \multirow{3}{*}{$\begin{array}{c}\text { Senin, } 28 \\
\text { November } 2017\end{array}$} & Pagi & $113,08 \mathrm{Mbps}$ & & $\mathrm{Ya}_{\mathrm{a}}$ \\
\hline & Siang & $121,49 \mathrm{Mbps}$ & & $\mathrm{Ya}$ \\
\hline & Sore & $122,43 \mathrm{Mbps}$ & & $\mathrm{Ya}$ \\
\hline \multirow{3}{*}{$\begin{array}{c}\text { Rabu, } 29 \\
\text { November } 2017\end{array}$} & Pagi & $121,65 \mathrm{Mbps}$ & & $\mathrm{Ya}_{\mathrm{a}}$ \\
\hline & Siang & $106,19 \mathrm{Mbps}$ & & Ya \\
\hline & Sore & $115,85 \mathrm{Mbps}$ & & $\mathrm{Ya}_{\mathrm{a}}$ \\
\hline \multirow{3}{*}{$\begin{array}{c}\text { Kamis, } 30 \\
\text { November } 2017\end{array}$} & Pagi & $113,59 \mathrm{Mbps}$ & & Ya \\
\hline & Siang & $93,83 \mathrm{Mbps}$ & & $\mathrm{Ya}$ \\
\hline & Sore & $117.40 \mathrm{Mbps}$ & & $\mathrm{Ya}$ \\
\hline \multirow{3}{*}{$\begin{array}{c}\text { Senin, } 4 \\
\text { Desember } 2017\end{array}$} & Pagi & $111,03 \mathrm{Mbps}$ & & Ya \\
\hline & Siang & $108 \mathrm{Mbps}$ & & Ya \\
\hline & Sore & $133,69 \mathrm{Mbps}$ & & Ya \\
\hline \multirow{3}{*}{$\begin{array}{c}\text { Selasa, } 6 \\
\text { Desember } 2017\end{array}$} & Pagi & $112,41 \mathrm{Mbps}$ & & $\mathrm{Ya}$ \\
\hline & Siang & $115,38 \mathrm{Mbps}$ & & $\mathrm{Ya}$ \\
\hline & Sore & $95,5 \mathrm{Mbps}$ & & Ya \\
\hline
\end{tabular}


Berdasarkan hasil penelitian di atas, implementasi jaringan komputer baru memang dapat memberikan peningkatan kualitas komunikasi data berdasarkan perbandingan throughput yang ditunjukkan pada gambar 4.1 dengan gambar 4.2 pada kampus B UNJ, peningkatan tersebut cukup signifikan karena sudah mendekati alokasi bandwidth yang diberikan pihak Internet Service Provider (ISP) dengan UPT TIK yaitu sekitar 120-130 Mbps. Peningkatan yang dilakukan dapat dikatakan berhasil karena sudah mampu memenuhi kebutuhan yang ada ditambah dengan hasil survei kecepatan Internet yang mayoritas menunjukkan angka 3 ke atas yang berarti cukup untuk kebutuhan mahasiswa, selain itu kondisi jaringan di kampus B sebelumnya tidak stabil karena beban jaringan dan sudah tidak optimalnya perangkat yang ada kini sudah sangat jarang terputus (jika terjadi, hanya karena faktor human error) dan dengan perangkat yang baru kinerja jaringan menjadi lebih optimal.

Hasil penelitian juga menunjukkan bahwa desain komunikasi data menggunakan switching dapat lebih cepat dan stabil dibandingkan dengan routing. Penggunaan switch yang dominan pada layer dua atau data-link layer dapat meningkatkan kualitas komunikasi data pada kampus B yang sebelumnya menggunakan router pada layer tiga atau network layer.

\section{Kesimpulan dan Saran}

Berdasarkan tahapan-tahapan tersebut dan dalam hasil pengujian didapatkan bahwa kualitas komunikasi data meningkat dan lebih stabil pada layer dua dibanding layer tiga, kecepatan Internet yang mendekati bandwitdh yang diberikan oleh ISP dan UPT TIK dan melebihi standar kecepatan AT\&T, perangkat kembali berjalan optimal, dan sudah jarang terjadi putus sambungan, menunjukkan bahwa desain dan implementasi yang dilakukan berhasil sesuai dengan yang diharapkan penulis. Sehingga kesimpulan yang didapat adalah peningkatan kualitas komunikasi data pada kampus B Universitas Negeri Jakarta dapat di implementasikan dengan tahapan penelitian ini.

Pada penelitian ini, agar jaringan berjalan dengan baik dibutuhkan teknisi yang mengerti permasalahan jaringan komputer. Beberapa implementasi yang dilakukan selalu dirasa kurang oleh user, hal ini karena user aka selalu merasa kurang dengan kualitas jarinan yang ada, oleh sebab itu diperlukan pengamatan agar didapat hasil yang lobjektif. Selain itu jaringan komputer yang ada perlu dilakukan pemeliharaan agar umur jaringan serta perangkatnya akan selalu berjalan optimal. Pada penelitian ini sudah tidak ditemukan masalah yang berarti, namun seiring dengan berkembangnya jaman, diharapkan jaringan yang telah diperbarui mapu bertahan dan ditingkatkan sesuai kebutuhan akademik kampus.

\section{Daftar Pustaka:}

AT\&T. (2016). Download Speed Calculator. https://www.att.com/esupport/speedcalculator/index.jsp. diakses pada 10 Desember 2017

Barnett, David, David Groth, \& Jim McBee. (2004). Cabling: The Complete Guide to Network Wiring, Third Edition. United States of America: SYBEX.

Cioara, J., D. Minutella, \& H. Stevenson. (2008). CCNA Exam Prep: (exam 640-802). Ed ke-2. United States on America: Pearson Education, Inc.

Cohen, William A. (2008). A Class with Drucker. Jakarta: Gramedia Pustaka Utama

Dede, Sopandi. (2008). Instalasi Dan Konfigurasi Jaringan Komputer. Bandung: Penerbit Informatika.

Empson, S. \& C. Schmidt. (2014). Routing and Switching Essentials Companion Guide. Indianapolis: Cisco Press.

Fakultas Ilmu Olahraga, UNJ. (2016). Ringkasan Ekseutif. http://fik.unj.ac.id/? page_id=1011 diakses pada 19 Desember 2017

Forouzan, B.A. (2007). Data Communications and Networking. Ed ke-4. New York: McGraw-Hill.

Janssen, Dale \& Cory Janssen. Data Communication. https://www.techopedia.com/ definition/6765/data-communications- $d c$ diakses pada 19 januari 2018

PT. Telekomunikasi Indonesia. Telkom Marketing Guides. http://www. telkomsolution.id/assets/media/pdf/pdf-telkomindonesia-product-.pdf. diakses pada 14 November 2017

Raja, Badia. (2015). Kualitas Jaringan Pada Jaringan Virtual Local Area Network (VLAN) Yang Menerapkan LINUX Terminal Server Project (LTSP). Jakarta: Universitas Negeri Jakarta.

Sofana, Iwan. (2011). Teori dan Modul Praktikum Jaringan Komputer. Bandung: Penerbit Informatika.

Tanenbaum, A.S. \& D.J. Wetherall. (2011). Computer Networks. Ed ke-5. Boston: Pearson Prentice Hall.

White, Curt M. (2010). Data Communication and Computer Networks. Ed ke-6. United States: Cengage Learning. 